\title{
Yazılım Projelerinde Karşılaşılan Risk Faktörleri ve Risk Yönetim Süreci
}

\author{
M. Hanefi CALP', M. Ali AKCAYOL ${ }^{2}$ \\ ${ }^{1}$ Bilişim Enstitüsü, Gazi Üniversitesi, Ankara, Türkiye \\ ${ }^{2}$ Bilgisayar Mühendisliği, Mühendislik Fakültesi, Gazi Üniversitesi, Ankara, Türkiye
}

\begin{abstract}
ÖZET
Günümüzde giderek yaygınlaşan yazılım projelerinde çok önemli hatalar meydana gelmektedir. Sözkonusu hatalar, geliştirilen yazılımları olumsuz yönde etkilemektedir. Dolayısıyla, bu durumu önlemek veya en aza indirmek için iyi kodlama yapmanın ötesinde "Yazılım Risk Yönetimi”" süreçlerinin başarıyla gerçekleştirilmesi gerekmektedir. Bu çalışmada, yazılım proje yönetimi kapsamında, risk tanımı, risk faktörleri, risk türleri, risk stratejileri ve risk yönetim süreci ayrıntılı ve karşılaştırmalı bir şekilde ele alınmıştır. Böylece, yazilım riskleri ve bu riskleri önleme yöntemlerini bilimsel olarak ortaya koymak suretiyle herhangi bir yazılımda oluşabilecek risklerin ortadan kaldırılması veya en azından azaltılması yönünde atılması gereken adımlar açıklığa kavuşturulmuştur. Çalışmanın bu alanla ilgilenen araştırmacılara önemli bir kaynak olması amaçlanmaktadır.
\end{abstract}

Anahtar kelimeler: Yazılım riski, Risk türleri, Risk faktörleri, Risk stratejileri, Risk yönetimi, Yazılım proje yönetimi

\section{Risk Factors and Risk Management Process Encountered in Software Project}

\begin{abstract}
There are very important problems that occur nowdays in the field of software projects ever widespreading. The respective problems has influenced software being developed negatively. Therefore, "Software Risk Management" processes must be carried out successfully beyond a good coding in order to avoid or to minimize this situation. In this study, within the scope of the software project management, risk identification, risk factors, risk types, risk strategies and risk management process are discussed in details and comparative. By revealing the software risks and the methods of prevention of these risks, the necessasy actions has been clarified to eliminate or to reduce the risks resulting from any software. This study is aimed at being an important reference for the researches interested in this field.
\end{abstract}

Keywords: Software risk, Risk types, Risk factors, Risk strategies, Risk management, Software project management

\section{GİRIŞ̧}

Dünyanın önemli endüstrilerinden biri olan yazılım endüstrisi, büyüklüğü ve insan yaşamındaki yeri ile günümüzde hatırı sayılır bir oranda dikkat çekmektedir. Bu endüstri tarafindan üretilen yazılımlar, hem üretim hem de tüketim olmak üzere güncel hayatın hemen her alanında kullanılmaktadır. Bu kapsamda akla gelen her alanla ilgili ihtiyaçların karşılanması için birçok proje hazırlanmaktadır. $\mathrm{Bu}$ projelerin minimum hata ile geliştirilmesi için, kaliteli bir kodlama yapmaktan ziyade "Yazılım Proje Yönetim Süreci"ndeki standartların en iyi şekilde uygulanması ve daha önce gerçekleştirilen projelerdeki hatalardan ders alınması gerekmektedir [1]. Bu durum ise; planlama yapma, tahmin etme, riskleri analiz etme, risk izleme ve iletişim gibi yönetime ait süreçlerin eksiksiz bir şekilde gerçekleştirilmesi ile mümkündür [2].
Yazılım projeleri, paydaşlar arasındaki anlaşmazlıklardan veya yanlış anlaşılmalardan ve beklenmeyen olumsuz sonuçlardan dolayı genel olarak daha fazla risk barındırmakta, daha fazla maliyetli olmakta ve bu durum geliştirilen yazılımın kalitesi olumsuz yönde etkilemektedir. Bu noktada yazılım kalitesi, temelde iki farklı bakış açışıla ele alındığında; müşteri gözünden kalite ve yazılım üreticisi gözünden kalite olarak isimlendirilebilir. Müşteriler, genel olarak satın aldıkları yazılımların; zamanında teslim edilmiş, kolay kullanılabilir, hatasız, tüm isteklerini karşılayan ve yeterli performansa sahip olmasını isterlerken; yazılım üreticileri ise; en uygun sürede, geliştirme ve bakım maliyetlerinin düşük ve üretilen yazılımın parçalarının bir sonraki projelerinde de kullanılabilir olmasını isterler $[3,4]$. Dolayısıyla, daha kaliteli bir yazılımın geliştirilmesi, yazılım risk yönetim sürecinin etkili bir şekilde icra edilmesi

Sorumlu yazar/Corresponding author: M. Hanefi CALP Tel: 0312-20238 05, e-posta: hcalp25@hotmail.com - mhcalp@gazi.edu.tr, Gönderilme/ Submitted: 08.08.2014, Kabul/Accepted: 02.03.2015 
ile mümkündür. Sonuç olarak, yazılım projelerinde risk yönetim faaliyetlerinin ne kadar zor ve önemli olduğu açıkça ortaya çıkmaktadır.

Risk yönetimi literatürde, bir endişenin kriz haline gelmeden üstesinden gelinmesi [5], riskleri belirleyip bu risklerin proje üzerindeki etkilerini minimize etme faaliyeti [6] veya riskleri yönetmek için kullanılan faaliyetler kümesi [7] olarak tanımlanmaktadır. Aynı zamanda, zararı azaltmaktan çok; para, zaman ve personel kaynaklarının kazanılması için fursatların belirlenip ilgili şahsın veya kurumun lehine çevrilmesini sağlayan mantıklı bir süreçtir [8].

IEEE'ye göre, yazılım projelerinde projeye ait risk faktörlerinin tanımlanma yüzdesi $\% 90$ iken, araştırma sonucunda risklerin tanımlanma yüzdesinin \%50-\%70 arasında olduğu ortaya çıkmıştır. Risk yönetim faaliyetleri, yazılım projeleri için \%700-\%2000 gibi bir değer arasında kazanç olarak geri dönüşe sahiptir. Zaman ve harcanan çaba göz önüne alındığında, risklerin ve olumsuz sonuçlarının önceden tespit edilip, öncelik sırası ve oluşma ihtimallerine göre birtakım tedbirlerin alınması gerekmektedir $[9,10]$.

Araştırmacılar, kapsamlı yazılım projelerinde risk yönetim faaliyetlerinin çok daha zor olduğunu savunmuş ve bu faaliyetlerin proje sürecindeki önemine özellikle dikkat çekmişlerdir [11]. 2004 y1lında, Standish Group International'ın yaptığı çalışmalarda ise, projelerin \% 53 'ünün gecikmiş ya da bütçeyi aşmış olduğu, \%18'inin terk edilmiş ya da değiştirilmiş olduğu ortaya konmuştur. $\mathrm{Bu}$ projelerin, yalnızca \% 29'u zamanında ve bütçeye uygun tamamlanmıştır. Yazılımların, bütçeyi aşmasının ve teslim süresinde gecikme olmasının nedeni; büyük oranda yönetimle ilgili olduğu için sorunu çözmede yönetimsel eylemleri araştırmak önemli hale gelmiştir. Dolayısıyla, yazılımlarda oluşabilicek risklerin önceden belirlenmesi ve yönetilmesi gerekmektedir [2].

Çalışmanın ikinci bölümünde, özet bir şekilde yazılım proje yönetimi ve yaşam döngüsü; üçüncü bölümünde, temel kavramlar başlığı altında risk tanımı, risk faktörleri ve araştırmacılar tarafından önerilen risk faktörlerinin karşılaştırılması, risk türleri ve risk yönetim stratejileri tanımlanmıştır. Dördüncü bölümde, risk yönetim süreci ayrıntılı bir şekilde ele alınmıştır. Son olarak beşinci bölümde ise, çalışmadan elde edilen sonuç ve öneriler kısmına yer verilmiştir.

\section{YAZILIM PROJE YÖNETIMII VE YAŞAM DÖNGÜSÜ}

Yazılım dünyasının gelişimine bakıldığında, yıllar geçtikçe geliştirilen yazılımların büyüklüğünün ve karmaşıklığının arttığ1 görülmektedir. Bu büyüme ve karmaşıklık, yazılımlarda hataların çok olması, güvenirlilik ve güvenliğin tam sağlanamaması gibi problemleri beraberinde getirmiştir [1]. Çalışılan uygulama alanının kritikliğine göre bu hataların doğuracağı sonuçların biçimi değişebilmektedir. Bir finans uygulamasında yapılan küçük bir hata çok büyük miktarlarda para kaybına yol açabilecekken, bir askeri uygulamada yapılması muhtemel küçük bir hata mal kaybının yanı sıra can kaybına da neden olma riskini taşımaktadır. Bu nedenle profesyonel kullanımı planlanan tüm yazılımların içerisindeki hataların bulunması ve düzeltilmesi gerekmektedir. Bu da yazılım projelerinin iyi yönetilmesi ile mümkündür [12].

$\mathrm{Bu}$ bağlamda Proje Yönetimi, proje gereksinimlerini karşılamak amacıyla, bilgi, beceri, araç ve teknikler uygulanarak başlama, planlama, yürütme, izleme, denetim ve kapanış işlemlerinin yürütülmesidir. Proje yönetimi kaynakların kullanımını (zaman, para, insan, mekân, vb.) etkili kılarken hedefleri tanımlama ve onlara ulaşma disiplinidir. Bu nedenle, zaman, maliyet, kapsam ve maddi olmayan varlıklar şeklinde sinıflandırılabilir.

Günümüzde yazılım hatalarının sebeplerini ortadan kaldıracak veya bu hataların oluşmasını engelleyecek çalışmalar yapılmaktadır. Ancak tüm bu çalışmalar yapılmasına rağmen yazılımlardaki veya projelerdeki hatalar tam manasiyla engellenememektedir [1]. Dolayısıyla, tam da bu noktada yazılım proje ve risk yönetiminin önemi ortaya çıkmaktadır.

$\mathrm{Bu}$ bağlamda yazılım proje yönetiminin yararlarını genel olarak şöyle sıralamak mümkündür;

1. Amaçlara ve hedeflere ne zaman ve nasıl ulaşılacağını önceden belirler.

2. Zaman planlaması yapılmasını zorunlu kılar.

3. Maliyet önceden belirlenir.

4. Kaynaklar önceden belirlenir.

5. Kullanılacak teknoloji belirlenir.

6. Kontrol sisteminin kurulmasını sağlar.

7. Belirli bir iş bölümü yapılmasını sağlar.

8. Proje üyelerini çok yönlü geliştirir [13].

Projenin gerçekleştirildiği aşamaları ifade eden "Yazılım Yaşam Döngüsü” boyunca proje yöneticisi, Şekil 1'de verilen faaliyetlerin yapılmasını sağlar. $\mathrm{Bu}$ faaliyetler, projenin bütçeyi aşmadan ve kalite hedeflerine uygun olarak zamanında teslim edilmesi için disiplinli bir yoldur. Ayrıca, Şekil 1'deki adımlar, yazılım proje yönetimi süreci 
içerisinde yazılım risk yönetiminin yerini de açıç̧a ortaya koyması açısından önem arz etmektedir.

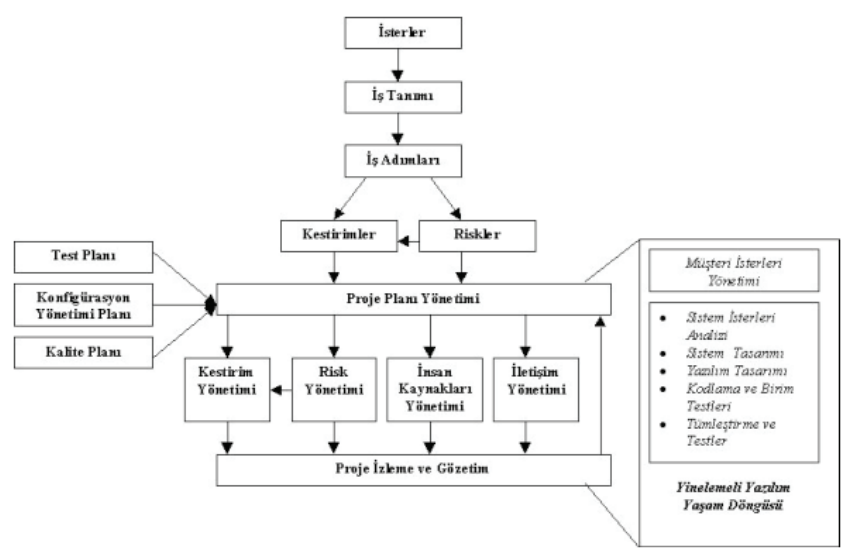

Şekil 1. Yazılım proje yönetimi blok şemas1 [2]

\section{TEMEL KAVRAMLAR}

Temel kavramlar başlığı altında risk tanımı, risk faktörleri, risk türleri ve risk yönetim stratejileri açıklanmıştır.

\subsection{Risk Tanımı}

Risk için literatürde farklı tanımlara rastlamak mümkündür. Ancak, hangi tanım olursa olsun, risk kavramı ile iki temel özellik anlatılmaktadır. Bu özellikler; kayıp ve olasılıktır. Kayıp ifadesiyle; zaman, para, itibar, kalite gibi konularda karşılaşılacak tehlikeler; olasılık ifadesi ile bu tehlikelerin oluşma potansiyeli anlatılmaktadır. Sonuç olarak riski; yazılım geliştirme projelerinde önceden tespit edilmesi ve çözüm üretilmesi gereken, bunlar yapılmadığında; emek, zaman, para, itibar vb. kayıplara neden olabilecek potansiyel tehlikeler olarak tanımlamak mümkündür [14]. Boehm ise yazılım riskini; başarılı bir yazılım geliştirme projesini tehlikeye atan, yanlış veya yetersiz bir yazılıma ya da yeniden çalışmalara neden olabilecek uygulama zorlukları, gecikmeler ya da belirsizlikler olarak tanımlamıştır [15].

\subsection{Yazılım Risk Faktörleri}

Literatür tarandığında, yazılım projeleri kapsamında araştırmacılar tarafından önerilen, kabul gören ve yaygın olarak kullanılan birçok risk faktörü bulunmaktadır. Bu faktörlerin belirlenmesi ve daha sonra kontrol edilmesi gerekmektedir [16,17]. Tablo 1'de, araştırmacılar tarafindan önerilen ve genel anlamda konuyla ilgili bir temel oluşturan risk faktörlerine yer verilmiştir.

\subsection{Yazılım Projelerinde Risk Türleri}

İncelenen kaynaklarda yazılım projelerinde karşılaşılan riskler genel olarak; zaman, bütçe (maliyet), yönetim, teknik, program, sözleşme/yasal riskler, personel ve diğer kaynaklı riskler olmak üzere sekiz başlık altında toplanmaktadır [5, 8, 21-25]. Tablo 2'de genel olarak risk türleri ve kısaca açıklamaları verilmiştir.

Tablo 1. Araştırmacılara göre yazılım risk faktörleri

\begin{tabular}{|c|c|c|c|}
\hline $\begin{array}{l}\text { Boehm (1991)'e göre } \\
\text { risk faktörleri [15] }\end{array}$ & $\begin{array}{l}\text { SEI (1996)'e göre } \\
\text { risk faktörleri [18] }\end{array}$ & $\begin{array}{c}\text { Conrow ve Shishido (1997)'e göre risk } \\
\text { faktörleri [19] }\end{array}$ & $\begin{array}{l}\text { Kansala (1997)’a göre risk } \\
\text { faktörleri [20] }\end{array}$ \\
\hline $\begin{array}{l}\text { - Personel eksikliği } \\
\text { - Gerçekçi olmayan } \\
\text { plan ve bütçeler } \\
\text { - Yanlış fonksiyon ve } \\
\text { özellik geliştirme } \\
\text { - Yanlış kullanıcı } \\
\text { arayüzü geliştirme } \\
\text { - Gereksiz özellikler } \\
\text { (Altın kaplama) } \\
\text { - Gereksinimlerin } \\
\text { sürekli değişmesi } \\
\text { - Harici eklenen } \\
\text { bileşenlerin eksikliği } \\
\text { - Harici uygulanan } \\
\text { görevlerin eksikliği } \\
\text { - Gerçek zaman } \\
\text { uygulama eksikliği } \\
\text { - Bilgisayar bilimi } \\
\text { yeteneklerinin } \\
\text { zorlanması }\end{array}$ & $\begin{array}{l}\text { - Ürün Mühendisliği } \\
\text { (Gereksinimler, } \\
\text { Tasarım) } \\
\text { - Geliştirme Ortamı } \\
\text { (Yönetim } \\
\text { süreci, } \\
\text { Geliştirme } \\
\text { sistemi) } \\
\text { - Program Kisıtları } \\
\text { (Kaynak, } \\
\text { Müşteri) }\end{array}$ & $\begin{array}{l}\text { - Aşırı, olgunlaşmamış, gerçekçi olmayan veya } \\
\text { kararsız gereksinimler } \\
\text { - Kullanıcı ilgi eksikliği } \\
\text { - Proje karmaşılığının küçümsenmesi } \\
\text { - Performans eksikliği } \\
\text { - Gerçekçi olmayan zamanlama planlama } \\
\text { tahminlerinin maliyeti } \\
\text { - Etkisiz proje yönetimi } \\
\text { - Etkisiz entegrasyon, derleme ve test, kalite } \\
\text { kontrol vb. } \\
\text { - Beklenmeyen kullanıcı arayüz zorlukları } \\
\text { - Olgunlaşmamış veya denenmemiş tasarım, } \\
\text { süreç veya teknolojiler } \\
\text { - Yetersiz iş planları veya konfigürsayon kontrolü } \\
\text { - Uygun olmayan metotlar veya araç seçimi veya } \\
\text { yanlış metrikler } \\
\text { - Eğitim düşüklüğü } \\
\text { - Yetersiz veya çok fazla dökümantasyon } \\
\text { - Yasa veya anlaşma konuları } \\
\text { - Eskime, modası geçme } \\
\text { - Beklenmeyen zorluklar ve taşeron ürünleri }\end{array}$ & $\begin{array}{l}\text { - Gereksinimlerin değişmesi } \\
\text { - Kilit personelin uygunluğu } \\
\text { - Kilit personelin bağımlılığı } \\
\text { - Diğer sistemler için arayüzler } \\
\text { - Gereksiz özellikler (Altın } \\
\text { kaplama) } \\
\text { - Müşteri sözleşmesi } \\
\text { - Sözleşme imzalanan kişinin } \\
\text { yeteneği } \\
\text { - Personelin analiz becerileri } \\
\text { - Alt projelerin teslimat } \\
\text { güvenilirliği } \\
\text { - İşlevsel modelin karmaşıklığı } \\
\text { - Personel sözleşmesi } \\
\text { - Yazılımın mantıksal } \\
\text { karmaşıklığ1 } \\
\text { - Yazılımın bakım } \\
\text { yapılabilirliği } \\
\text { - Proje yöneticisinin uygunluğu } \\
\text { - Veri modelinin karmaşıklığı }\end{array}$ \\
\hline
\end{tabular}


Tablo 2. Risk türleri ve açıklamaları

\begin{tabular}{|c|c|}
\hline Risk Türleri & Açıklama \\
\hline Zaman riskleri & $\begin{array}{l}\text { Projenin, yanlış görev ve malzeme paylaşımından dolayı beklenen süre içerisinde gerçekleşmesine } \\
\text { veya tamamlanmasına engel olan veya sebep olan risk çeşididir. }\end{array}$ \\
\hline $\begin{array}{l}\text { Bütçe (maliyet) } \\
\text { riskleri }\end{array}$ & $\begin{array}{l}\text { Gerçekçi olmayan bütçe tahminleri sonucu finansal sorunlara yol açan risklerdir. Bu risklerin } \\
\text { gerçekleşmesi durumunda Tablolar değişmekte, maliyetler artmaktadır. }\end{array}$ \\
\hline Yönetim riskleri & $\begin{array}{l}\text { Yönetim riskleri; amaçların net olmayışı, planlama eksikliği, yönetim tecrübesi ve eğitim eksikliği, } \\
\text { iletişim sorunları, örgütsel sorunlar, otorite eksikliği ve kontrol problemlerini kapsamaktadır. }\end{array}$ \\
\hline Teknik riskler & $\begin{array}{l}\text { Genelde fonksiyonların yanlış olmasından kaynaklanır. Müşteri taleplerinin sürekli değişmesi, gelişmiş } \\
\text { tekniklerin kullanılmaması ve geliştirilecek olan projenin zor faaliyetler içermesi gibi sebeplerden } \\
\text { kaynaklanmaktadır. }\end{array}$ \\
\hline Program riskleri & $\begin{array}{l}\text { Proje kapsamının dışına çıkan, kontrol dışı durumlardan veya önceliklerin sürekli değişmesinden } \\
\text { doğan risklerdir. }\end{array}$ \\
\hline $\begin{array}{l}\text { Sözleşme ve yasal } \\
\text { riskler }\end{array}$ & $\begin{array}{l}\text { Sözleşme ve yasal riskler; değişen ihtiyaçları, pazar odaklı programları, sağlık ve güvenlik sorunları, } \\
\text { hükümet düzenlemeleri ve ürün garantisi konularını içerir. }\end{array}$ \\
\hline Personel riskleri & $\begin{array}{l}\text { Personel riskleri; personel duraklamaları, deneyim ve eğitim sorunları, etik ve ahlak konularını, } \\
\text { personel çatışmalarını ve verimlilik sorunlarını içermekedir. }\end{array}$ \\
\hline $\begin{array}{l}\text { Diğer kaynaklı } \\
\text { riskler }\end{array}$ & $\begin{array}{l}\text { Diğer kaynaklı riskler, mevcut olmayan veya geç teslim edilen ekipman ve sarf malzemeleri, yetersiz } \\
\text { aracı, yetersiz tesisleri, dağıtılan bölgeleri, bilgisayar kaynaklarının olmayışı ve yavaş tepki sürelerini } \\
\text { kapsamaktadır. }\end{array}$ \\
\hline
\end{tabular}

\subsection{Yazılım Risk Yönetim Stratejileri}

Yazılım risk yönetim stratejileri temel anlamda tepkisel (reaktif) ve önleyici (proaktif) olmak üzere iki şekilde ele alınmaktadır.

\subsubsection{Tepkisel (Reaktif) Risk Stratejisi}

$\mathrm{Bu}$ tepkisel (reaktif) strateji, muhtemel riskler için projeyi izler. Ayrılan kaynakların etkili bir şekilde kullanılması ile bu risklerle başa çıkılması için sözkonusu risklerin gerçek problem haline gelmesi gerekmektedir. Yazılım ekibi, genelde bir şeyler yanlış gidene kadar riskler hakkında hiçbirşey yapmaz. Sorun oluştuktan sonra, ekip sorunu düzeltmek için hızlı bir şekilde girişimde bulunur ve bu durum "yangın söndürme modu" olarak adlandırılır. Bu girişim başarısız olduğunda, "kriz yönetimi” devreye girer ve proje gerçek manada tehlikede demektir.

\subsection{2. Önleyici (Proaktif) Risk Stratejisi}

Önleyici (proaktif) risk stratejisi, risk yönetimi için çok daha akıllı bir stratejidir. Bu strateji, teknik çalışmalar başlatılmadan çok önce başlar. Olasılık ve etkileri değerlendirilen potansiyel riskler tanımlanır ve önem derecesine göre sıralanırlar. Sonra, yazılım ekibi risk yönetimi için bir plan hazırlar. Birincil amaç, riskten sakınmaktır. Fakat tüm risklerden sakınmak mümkün olmadığı için ekip, kontrollü ve etkili bir şekilde cevap vermesine olanak sağlayacak bir acil durum planı geliştirmek için çalışır [26].

\section{RISKK YÖNETIM SÜRECİ}

Risk yönetimi, Wiegers (2005) tarafindan, projeye zarar vermeden önce, potansiyel problemlerin tanımlanmas1, hangi alanlarda ortaya çıkabileceğinin belirlenmesi ve yok edilmesi olarak tanımlanmıştır. Yukarıdaki tanımdan anlaşılacağı gibi risk yönetimi; proje yönetiminin bir parçası şeklinde algılanarak, proje yönetimi ile beraber hatta daha önce başlatılması ve proje geliştirme süresince ve destek aşamasında da devam edilmesi gereken bir süreç olarak görülmelidir. Bu nedenle, "önleyici (proaktif) davranış" ve "süreklilik" risk yönetimi için anahtar kelimelerdir [27].

ISO/IEC Standard 16085:2006 standardına göre risk yönetiminin amac1, gerçekleștirilecek risk yönetiminin kapsamının belirlenmesi, uygun risk yönetimi stratejilerinin tanımlanması ve uygulanması, risklerin sürekli olarak tanımlanması, analiz edilmesi, ele alınması ve izlenmesidir. Sürecin başlangıç girdileri; hedefler, kaynaklar, zaman cetveli, bütçe ile organizasyon ve işlevlerine ilişkin bilgidir (geçmişe yönelik olanlar dâhil). Sürecin sonunda riskler hakkında sürekli güncellenen bilgiler, önceden tanımlanmış ve belirlenmiş risk kontrol eylemleri, risk ve risk yönetimine ilişkin veri ve tecrübeler elde edilecektir. 
Risk yönetiminin başarılı bir şekilde sonuçlanması için aşağıda verilen maddelerin eksiksiz bir şekilde gerçekleştirilmesi gerekmektedir;

a) Gerçekleştirilecek risk yönetiminin kapsamının belirlenmesi,

b) Uygun risk yönetimi stratejilerinin tanımlanması ve uygulanmas1,

c) Risklerin proje boyunca tanımlanması,

d) Risklerin analiz edilmesi ve ele alınmaları için gereken kaynakların önceliklerinin belirlenmesi,

e) Risk durumundaki degişikliklerin ve risk ele alma faaliyetlerinin ilerlemesinin tanımlanması, uygulanması ve değerlendirilmesi için risk ölçüm yöntemlerinin tanımlanması ve

f) Riskin etkisini düzeltmek veya etkiden kaçınmak için öncelik, olasılık ve sonucuna göre riskin uygun şekilde ele alınmasi [28].

Konuyla ilgili olarak alt süreçlere göre farklılık gösteren bazı risk yönetim süreç metotları Tablo 3’te verilmiştir. Burada özellikle, Boehm metodolojisini tanımlarken her alt süreç için liste yönteminden maliyet analizlerine kadar pek çok yöntemin kullanılmasını anlatmıştır. Ancak, bu yöntemlerden hiçbirini kesinlikle kullanılması gereken standart yöntemler olarak göstermemiş, bu konuda esnek bir yaklaşım izlemiştir [14,15].

Tablo 3. Literatüre göre araştırmacıların önerdikleri bazı risk yönetim süreçleri ve adımları

\section{Yöntem}

Wiegers Yöntemi (2005)

[27]

ISO/IEC Standard

16085:2006 [28]

Barry W. Boehm Yöntemi [15]

\section{Sürecin Adımları}

- Potansiyel Problemlerin Tanımlanması

- Problemlerin Hangi Alanlarda Ortaya Çıkabileceğinin Belirlenmesi

- Problemin Yok Edilmesi

- Gerçekleştirilecek Risk Yönetiminin Kapsamının Belirlenmesi

- Uygun Risk Yönetimi Stratejilerinin Tanımlanması ve Uygulanması

- Risklerin Sürekli Olarak Tanımlanması

- Risklerin Analiz Edilmesi

- Risklerin Ele Alınması

- Risklerin İzlenmesi

Risk Değerlendirme (Tanımlama, Analiz ve Önceliklendirme)

Risk Kontrolü (Planlama, Çözümleme ve Gözleme)

- Risk Faktörlerini Tanımlamak

- Risk Olasılıklarını ve Proje Üzerine Etkilerini Değerlendirmek

- Tanımlanan Riskleri Azaltmak veya Ortadan Kaldırılması İçin Strateji Geliştirmek

Richard Fairly Yöntemi [29] - Risk Faktörlerini Gözlemek

- İhtiyaç Halinde Acil Durum Planına Başvurmak

- Acil Durum Planının Yetersiz Kalması Durumunda Kriz Yönetimini Uygulamak

- Krizden Kurtulmak

- Fonksiyonel Çözümleme (İhtiyaç, Ürün, Süreç, İnsan, Yönetim, Çevre ve Yazllım Geliştirme Konularını Dikkate Alan)

Chittister ve Haimes Risk Yönetim Metodu [30]

Rockwell'in Risk Yönetim Süreci (1995) [31]

Genel olarak [32-35]
- Kaynak-Temelli Çözümleme (Donanım, Yazılım, Organizasyon, İnsan Başlıklarını İçeren Dört Başarısızlık Alanını İnceleyen)

- Zamana Bağlı Çözümleme (Yazılım Süreçlerini Kapsayan)

- Risklerin Tanımlanması

- Risk Karakterlerinin Anlaşılması

- Önceliklendirilmesi

- Önlenmesi

- İzleme/Kontrol

- Risk Tanımlama

- Risk Analizi

- Risk Planlama

- Risk Kontrolü

- Risk İzleme 
Risk yönetimi denilince ilk akla gelen; performans, maliyet ve zaman risklerine sebep olan etkenlerin sürekli takip edilmesi, risk azaltıcı tedbirlerin alınması ve risklerin izlenmesidir [8]. Tablo 4'te ise, araştırmacıların önerdiği risk yönetim süreci adımlarının karşılaştırmalı analizine yer verilmiştir. Tüm bu tablolar, detaylı bir şekilde incelendiğinde, risk yönetim.sürecinde genel olarak Şekil 1 'de belirtilen adımların gerçekleştiği ortaya çıkmaktadır. Şekil 2'de risk yönetim sürecinin genel şeması verilmiş olup, her birinin görevi ayrıntılı olarak açklanmıştır.

Risk yönetim sürecinin ilk adımına geçmeden önce risk yönetimi uygulama esasları belirlenmektedir. Risk yönetimi uygulama esasları, bir projede risk yönetiminin nasıl uygulanacağı konusuna açıklık getirir. Sözkonusu esasların belirlenme süreci; projenin başlatılması, proje ilgililerinin değişmesi ve projenin tüm risk seviyesinin değişmesi durumlarında başlatılır ya da yenilenir. Bu süreçte, aşağıda ifade edilen işlemler yapılır.

Risk yönetimi için temel hedeflerin belirlenmesi,

Risk yönetiminin ilgi alanının belirlenmesi (hangi risk alanları üzerinde çalışılacak ve çalışmalar hangi seviyede detaylandırılacak),

Risk yönetimi yetkisinin belirlenmesi uygun bütçenin veya yetkinin tanımlanması,

Kabul edilmiş risklerin belirlenmesi,

Risk yönetimi işlemleri, yöntemleri veya tekniklerinin tanımlanmas1,

Proje ilgilileri ve önceliklerinin tanımlanması.
Risk yönetimi uygulama esasları belirlendikten sonra hedefler belirlenir. Hedeflerin belirlenmesi sürecinin amacı, proje hedeflerini açıkça tanımlamak ve tüm proje ilgilileri ile hedeflerini dikkate almaktır. Bu kapsamda hedef belirleme süreci; proje planlamasının başlaması, yeni hedefler veya proje ilgilileri belirlenmesi durumunda başlatılır. Süreç içinde var olan hedef tanımları incelenerek, gerekirse daha açık hedef tanımları yapılır. Farklı proje ilgilileri, onların öncelikleri, önemleri ve hedeflerine yönelik beklenti seviyeleri belirlenir. Sürece girdi sağlayan unsurlar; proje yetki bilgisi, hedefler, kaynaklar, zaman cetveli, bütçe ve organizasyon tarafından belirlenen risk yönetimi esaslarıdır. $\mathrm{Bu}$ sürecin tamamlanması ile hedeflerin açıkça belirlenmesi ve tüm katılımcıların fikir birliğine varmaları gerekmektedir. Konuyla ilgili olarak hedeflerin tespit edilebileceği alanlar aşağıda belirtilmiştir:

proje geliştirme süreci,

kullanılan kaynaklar (çoğunlukla personel ve zaman), proje geliştirme maliyeti,

ürün ihtiyaçları (fonksiyonellik ve diğer karakteristik özellikler),

kaynak kullanımı,

teknik sınırlamalar (donanım platformu, çalışan sistemler ve özel yazılım araçlarının kullanılması) [14].

Risk yönetim uygulama esasları ve hedefler belirlendikten sonra risk yönetim sürecinin ilk adımı olan risk tanımlama faaliyeti gerçekleştirilmektedir.

Tablo 4. Risk yönetim sürecinin araştırmacılara ve ilgili kuruluşlara göre karşılaştırılması

\begin{tabular}{|c|c|c|c|c|c|c|c|c|c|}
\hline $\begin{array}{c}\text { Risk Yönetim Süreci } \\
\text { Adımları }\end{array}$ & $\begin{array}{c}\text { Boehm } \\
{[36]}\end{array}$ & $\begin{array}{c}\text { ISO/IEC } \\
{[37]}\end{array}$ & MSF [38] & $\begin{array}{l}\text { RUP } \\
{[39]}\end{array}$ & ISO [40] & $\underset{[41]}{\mathrm{AS} / \mathrm{NZS}}$ & $\begin{array}{c}\text { CMMI } \\
{[42]}\end{array}$ & $\begin{array}{c}\text { MPS, BR } \\
{[43]}\end{array}$ & $\begin{array}{c}\text { PMBoK } \\
\text { [44] }\end{array}$ \\
\hline Yönetimi planlama & & $\sqrt{ }$ & & $\sqrt{ }$ & & $\sqrt{ }$ & $\sqrt{ }$ & $\sqrt{ }$ & $\sqrt{ }$ \\
\hline Tanımlama & $\sqrt{ }$ & $\sqrt{ }$ & $\sqrt{ }$ & $\sqrt{ }$ & $\sqrt{ }$ & $\sqrt{ }$ & $\sqrt{ }$ & $\sqrt{ }$ & $\sqrt{ }$ \\
\hline Nitel analizi hazırlama & $\sqrt{ }$ & $\sqrt{ }$ & $\sqrt{ }$ & $\sqrt{ }$ & $\sqrt{ }$ & $\sqrt{ }$ & $\sqrt{ }$ & $\sqrt{ }$ & $\sqrt{ }$ \\
\hline Nicel analizi hazırlama & $\sqrt{ }$ & $\sqrt{ }$ & $\sqrt{ }$ & $\sqrt{ }$ & $\sqrt{ }$ & $\sqrt{ }$ & $\sqrt{ }$ & $\sqrt{ }$ & $\sqrt{ }$ \\
\hline Sonuçları planlama & $\sqrt{ }$ & $\sqrt{ }$ & $\sqrt{ }$ & $\sqrt{ }$ & $\sqrt{ }$ & $\sqrt{ }$ & $\sqrt{ }$ & $\sqrt{ }$ & $\sqrt{ }$ \\
\hline Analiz & $\sqrt{ }$ & $\sqrt{ }$ & $\sqrt{ }$ & $\sqrt{ }$ & $\sqrt{ }$ & $\sqrt{ }$ & $\sqrt{ }$ & $\sqrt{ }$ & $\sqrt{ }$ \\
\hline İzleme ve Kontrol & $\sqrt{ }$ & $\sqrt{ }$ & $\sqrt{ }$ & $\sqrt{ }$ & $\sqrt{ }$ & $\sqrt{ }$ & Kismen & $\sqrt{ }$ & $\sqrt{ }$ \\
\hline Raporlama & & & Kismen & & Kismen & $\sqrt{ }$ & Kismen & & Kismen \\
\hline Öğrenme & & & & & Kismen & Kismen & Kismen & & Kismen \\
\hline
\end{tabular}




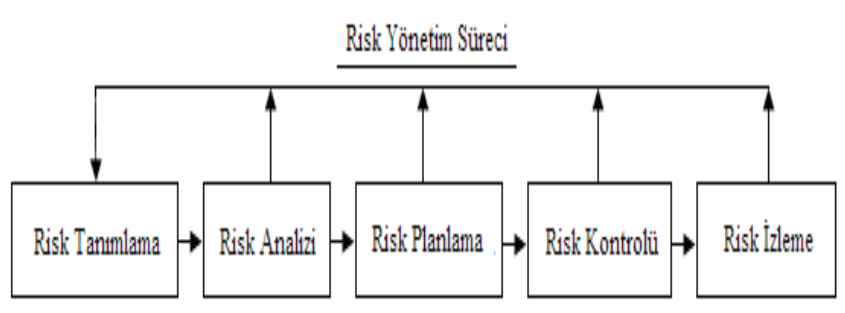

Şekil 2. Risk yönetim süreci

\subsection{Risk Tanımlama}

Riskin tanımlanması; projeyi olumsuz etkilemesi beklenen risk faktörlerinin ortaya konulmasıdır. Sadece proje başlangıcında gerçekleştirilen bir faaliyet olmayıp, proje süreci içerisinde ve bu süreç boyunca periyodik olarak gerçekleştirilmektedir. Bu süreci sürdürmenin en iyi yolu, uygun kişileri bir takım halinde bir araya getirmektir. Sürecin hedefi, projeye yönelik risklere ilişkin mantıklı bir liste elde etmektir. Sürecin zihinsel bölümünde sadece potansiyel tehditlerin neler olabileceği ortaya konur. $\mathrm{Bu}$ süreçte riskler analiz edilmez. Risklerin analizi bir sonraki adımda gerçekleştirilecektir. Risk tanımlama ile ilgili olarak çok çeşitli teknikler kullanılabilmektedir. Bunlar; beyin firtınası, simülasyon, senaryo analizi, öngörüşmeler ve prototipleme, kontrol listeleri, akış şemalar ve uzman şahıslar ile görüşmeler'dir [8, 32, 34, 45, 46]. Bu süreç için sağlanacak girdiler; hedefler, kaynaklar, zaman cetveli, bütçe, risk yönetimi uygulama esasları, risk kontrol listeleri ve daha önceki projelerden öğrenilen derslerdir [44]. Risklerin tanımlanması süreci sonunda oluşturulacak listede risklere numara veya kod verilmesi, daha sonraki adımlarda riskin takip edilmesinde kolaylık sağlamaktadır. Risk tanımlama sürecinde; yazılım proje yöneticisi, takım üyeleri, risk yönetim ekibi, paydaşlar, müşteriler ve ekip harici risk yönetim uzmanları bulunabilirler [34]. Sonuç itibariyle bu süreçte, bir risk listesi oluşturulur ve olabilecek ilaveler, gelişmeler ve onaylar için tüm paydaşlarla görüşülerek sözkonusu liste güncellenir [47]. Şekil 3'te risk tanımlama süreci verilmiştir.

\subsection{Risk Analizi}

Risk analizi sürecinde, öncelikle herbir tanımlı risk ve etkileri, olasılıkları, şiddetleri bağımsız bir şekilde değerlendirilerek analiz edilir [35]. Analiz; metrikler, karar ăgaçları ve senaryo analizleri gibi farklı teknikler kullanılarak yapılabilir [34]. Daha sonra riskler önceliklendirilir ve en öncelikli risk listesi oluşturulur [15]. Analiz sonuçlarına göre, her bir risk veya risk gruplarını yönetmek için bir plan önerilir. Son olarak, öncelikli risk listesi, onay için paydaşlarla görüşülür [47].

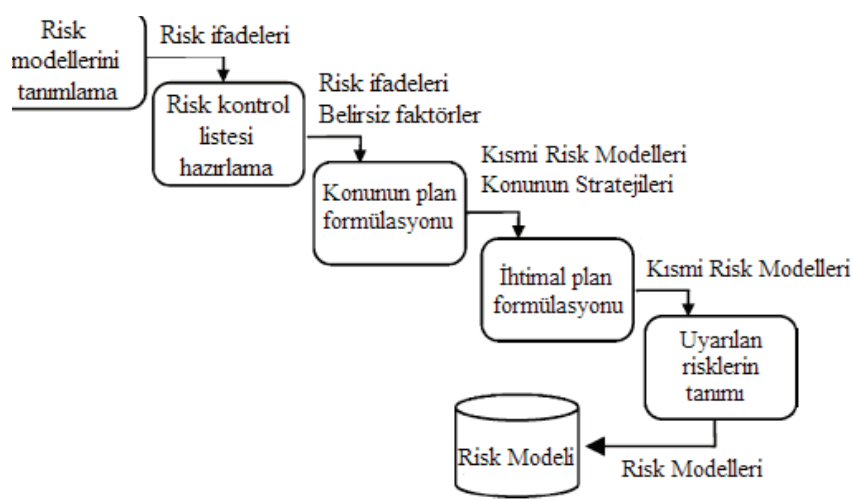

Şekil 3. Risk tanımlama süreci [45]

$\mathrm{Bu}$ sürecin hedefi; risk senaryolarını hazırlamak ve risk kontrol eylemlerinin planlanabilmesi için proje risklerini detaylı olarak tanımlamaktır. Risk analizi süreci; risklerin olasılıklarını, etkilerini hesaplayabilmek ve önemli riskleri belirlemek için risk bileşenlerinin analiz edilmesi sürecidir. Süreç, ilk risk değerlendirmesinde ve her yeni tespit edilen risk için yeniden başlatılacaktır. Sürecin girdisi, risk listesidir. Çıktısı ise, önemli riskler konusunda sürece katılan personelin fikir birliği ile üretilen önceliklendirilmiş risk senaryolarıdır. Risk analizi sürecinde temel olarak iki alt süreç gerçekleştirilmektedir. Bunlardan; birincisi seçilen risklerin senaryolar halinde belgelendirildiği "risk senaryosu geliştirme”, ikincisi ise risk senaryolarının sıralanarak "önceliklendirilmesi” dir.

\subsubsection{Risk Senaryosu Geliştirme}

Risk senaryosu geliştirme alt süreci, temel riskler için senaryolar geliştirmeyi amaçlayan ve bu maksatla analiz grafiği (Şekil 4) ve diğer çizim araçlarının kullanıldığı, süreç çıktısı olarak en muhtemel riskler için risk senaryolarının üretildiği ve proje yöneticisinin sorumlu olduğu bir süreçtir. Geliştirilen senaryo için örnek bir analiz grafiği Şekil 5’te verilmiştir.

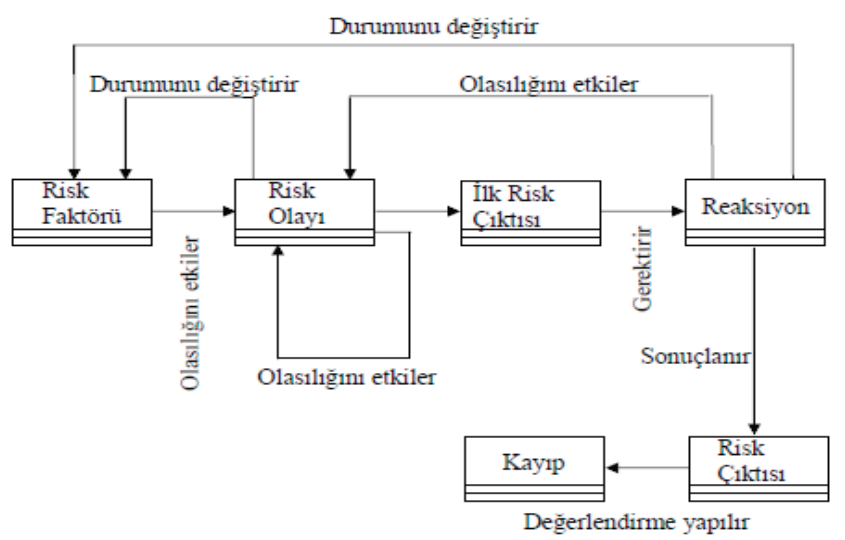

Şekil 4. Analiz grafiği [14] 


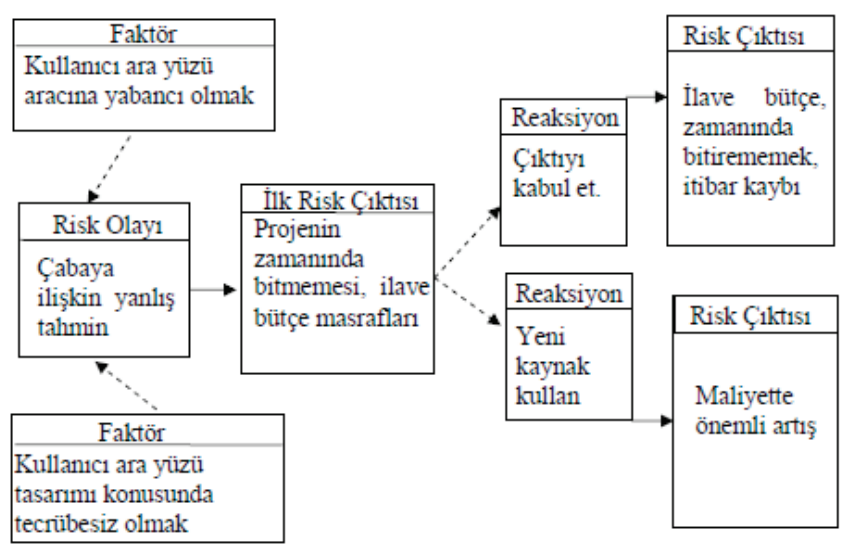

Şekil 5. Örnek senaryo grafiği [14]

Risk maddelerinin seçilmesi, bir sonraki adım olan risk önceliklendirmeye de katkı sağlayacaktır. Tüm risk maddeleri gözden geçirilerek hangilerinin analiz sürecine dâhil edileceği açıkça belirtilmelidir. Bu konuda kural, en önemli risklerin seçilerek senaryolaştırılması ve risk grupları içinde kalan diğer risk maddeleri için ilerleyen zamanda risk kontrol eylemleri gerçekleştirilinceye kadar senaryo geliştirmeye devam etmektir.

\subsubsection{Risk Önceliklendirme}

Risk yönetimi için ayrılan kaynakların sınırlı olması nedeniyle, tüm risk senaryolarının analiz edilmesi veya ortadan kaldırılması mümkün olamamaktadır. Bunun yerine önemli riskler üzerinde odaklanmak, zaman ve kaynak ayırarak onları yönetmek daha uygundur. Bunun başarılması için risk senaryolarının önem derecelerine göre sıralanması gerekmektedir. Risk senaryolarının önceliklendirilmesi için, her bir riske göre fayda kaybının ve ihtimalinin hesaplanmasına ihtiyaç vardır. Bu iki tahmin problemi, çok çeşitli zorlukları da beraberinde getirmektedir. Prensipte geçmişe yönelik elde mevcut bilgilerin yetersiz olması ve çevrenin sürekli değişmesi hususlarına bağlı olarak, ihtimal hesabı yapmak çok zordur. Hatta bazen imkânsızdır. Fayda kaybının tahmin edilmesine ilişkin zorluk ise, dikkate alınması gereken faktörlerin çokluğundan ve her bir proje ilgilisi için faydanın hangi yapıda olduğunun tam olarak bilinmemesinden kaynaklanmaktadır. Önceliklendirme sürecinde, senaryoların olasılık ve fayda kaybı sıralamaları kullanılmakta ve senaryoların diğerlerine göre orantısal etkinlikleri araştırılmaktadır. Tablo 5'te senaryolar, sıralamalarına uygun olarak gösterilmiş olup, bir senaryonun diğer senaryolara göre orantısal olarak üstün olduğu kolayca görülmektedir. Yani, senaryoların orantısal etkinliği, yukarıdan aşağı ve soldan sağa doğru sıralanmaktadır.
Tablo 5'e bakıldığında; 3. ile 5. senaryolar farksız ve 5 . senaryo, 7. senaryodan yüksek kabul edilebilir. Senaryo sıralamaları, proje ilgililerine bağımlıdır. Analiz içinde birden fazla proje ilgilisi ifade ediliyorsa, bu sayı ile uyumlu miktarda fayda kaybından da bahsetmek gerekir. Ancak, proje ilgilileri aynı ve ürün niteliklerini ifade eden öncelikler benzer ise karışıklığı önlemek için bunların aynı sütunda toplanması da mümkündür. Proje ilgilisini dikkate alan bu bakış, risk kontrol planlaması sürecinde; risk senaryosu için kontrol eylemlerinin belirlenmesi, seçimi ve bu konudaki maliyetlere kimlerin katlanması gerektiğini ifade etmesi açısından önemlidir [14].

Tablo 5. Risk senaryo sıralaması orantı etkinliği [14]

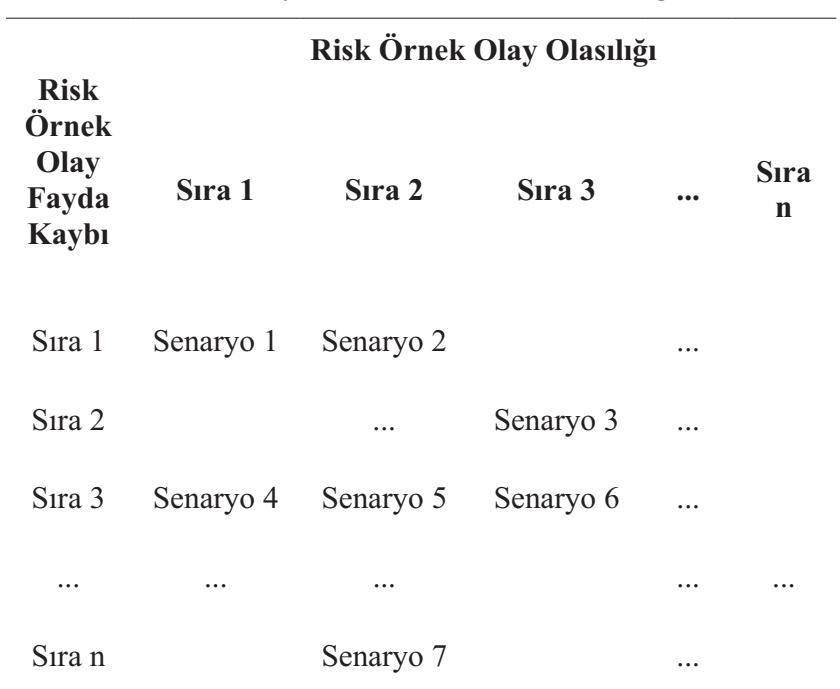

\subsection{Risk Planlama}

Risk planlama aşamasında, tanımalanan riskleri yönetmek için strateji, seçenek ve eylem planları oluşturulur. Bu evre; risk listesi, analiz sonuçları, risk eylem planları ve ön planlar oluşturularak başlar [47, 48]. Risk planlama faaliyetlerini şu şekilde sıralamak mümkündür;

- risk listesi, analiz sonuçları ve öncelik planları için bir çalışma yapma,

- riskleri yönetmek için stratejiler belirleme,

- seçilen risk stratejilerini uygulayarak risk yönetim planı oluşturma,

- kontrol ve izleme planı oluşturma,

- eylem planı oluş̧urma,

- ihtimal planını oluşturma (gerekirse),

- planları uygulamak için çerçeve planı oluşturma,

- kisitları belirleme, 
- çabayı tahmin etme,

- kaynakları tahmin etme,

- bütçe tahsis etme,

- riskleri yönetmek için sorumlu rolleri atama,

- risk yönetim planları içerisindeki tüm planları birleştirme,

- risk yönetim planını analiz etme,

- sözleşme ile ilgili riskleri hazırlama,

- $\quad$ risk yönetim planını ilgili paydaşlara iletme,

- $\quad$ risk yönetim planını güncelleme (gerekirse),

- risk yönetim planını onaylama,

- $\quad$ risk yönetim plan dökümanını güncelleme [47].

Planlara örnek olarak "Risk planı" ve "Risk Yanıt Planı" Tablo 6 ve 7'de verilmiştir.
Tablo 6. Risk plan örneği

\begin{tabular}{|c|c|c|c|c|}
\hline \multirow{2}{*}{$\begin{array}{c}\begin{array}{c}\text { Analiz takım } \\
\text { üyeleri }\end{array} \\
\text { Risk }\end{array}$} & \multicolumn{4}{|c|}{ Ahmet ABC, Leyla ABB, gibi. } \\
\hline & $\begin{array}{c}\text { Olasılık } \\
(1-10)\end{array}$ & $\begin{array}{l}\text { Etkisi } \\
(1-10)\end{array}$ & $\begin{array}{c}\text { Öncelik } \\
\text { (1-10) }\end{array}$ & Faaliyetler \\
\hline $\begin{array}{c}\text { Kullanıcının } \\
\text { geliştirilecek } \\
\text { yazılıma yabancı } \\
\text { olması }\end{array}$ & 5 & 6 & 6 & $\begin{array}{c}\text { Kullanıcilara } \\
\text { eğitim verilecek. } \\
\text { Belirli peryotlarla } \\
\text { tanitım toplantıları } \\
\text { yapılacak. }\end{array}$ \\
\hline $\begin{array}{l}\text { Gerçekleştirilen } \\
\text { her adımın not } \\
\text { alınamaması ve } \\
\text { raporlanamaması }\end{array}$ & 3 & 2 & 4 & $\begin{array}{l}\text { Yeni personel } \\
\text { alınacak. }\end{array}$ \\
\hline
\end{tabular}

Tabloda belirtilen (1-10) skalasında 1: En düşük; 10: En yüksek düzeyi temsil etmektedir.

Tablo 7. X Proje Performansının Risk Yanıt Planı

\begin{tabular}{|c|c|c|c|c|c|}
\hline $\begin{array}{l}\text { Sira } \\
\text { No }\end{array}$ & Risk Faktör Adı & $\begin{array}{l}\text { Önceki Risk } \\
\text { Seviyesi }\end{array}$ & $\begin{array}{c}\text { Risk Yanit } \\
\text { Stratejisi }\end{array}$ & Risk Yanıt Planı & $\begin{array}{l}\text { Son Risk } \\
\text { Seviyesi }\end{array}$ \\
\hline 1 & Personel yetersizliği & Düşük & Kabul Et & $\begin{array}{l}\text { Personel Ataması } \\
\text { Yapıldı. }\end{array}$ & Düşük \\
\hline 2 & $\begin{array}{l}\text { Kaynak alımlarının tahmin edilenden fazla } \\
\text { gerçekleşmesi }\end{array}$ & Normal & Kaçin & Bütçe ilavesi yapıldı. & Çok Düşük \\
\hline 3 & $\begin{array}{l}\text { Projenin planına göre yönetilmesinde } \\
\text { aksaklıklar meydana gelmesi }\end{array}$ & Çok Yüksek & Azalt & $\begin{array}{l}\text { Yöneticiye eğitim } \\
\text { verildi. }\end{array}$ & Düşük \\
\hline 4 & $\begin{array}{l}\text { Sözleşme metninde değişiklikler meydana } \\
\text { gelmesi }\end{array}$ & Normal & Kaçın & $\begin{array}{l}\text { Ayrıntılı sözleşme } \\
\text { metni hazırlandı. }\end{array}$ & Çok Düşük \\
\hline 5 & $\begin{array}{l}\text { Ekipman ve sarf malzemesi tesliminde } \\
\text { gecikmeler olmasi }\end{array}$ & Yüksek & Transfer Et & $\begin{array}{l}\text { Alternatif tedarikçiler } \\
\text { belirlendi. }\end{array}$ & Düşük \\
\hline 6 & $\ldots \ldots \ldots \ldots \ldots \ldots$ & $\ldots \ldots \ldots$ & $\ldots \ldots \ldots$ & $\ldots \ldots \ldots$ & $\ldots \ldots \ldots$ \\
\hline
\end{tabular}

\subsection{Risk Kontrolü}

$\mathrm{Bu}$ adımda, planlama ve uygulama faaliyetleri gerçekleştirilmektedir. Sürecin planlama bölümünde amaç, risk kontrol eylemlerinden maliyet etkin olanlarının önerilmesi ve seçilmesidir. Bu kapsamda, temel işlev hangi risklerin en büyük tehdidi ortaya çıkaracağını belirlemek ve riski ortadan kaldırmak veya azaltmak için uygun risk kontrol eylemini seçmektir. Sürecin girdisi, kısmen önceliklendirilmiş risk senaryolarıdır. Sürecin çıktısı ise, seçilmiş risk kontrol eylemleri ve risk izleme ölçekleridir. Bu sürecin yürütülmesi sorumluluğu da proje yöneticisine aittir. $\mathrm{Bu}$ hedeflerin gerçekleştirilmesi için risk senaryolarının ve risk kontrol eylemlerinin siralanması gerekmektedir. Yani, risk kontrol planlama, olası risk kontrol eylemlerinin belirlenmesi ve uygulanacak maliyet-etkin risk kontrol yönteminin seçimidir. Bu süreçlerin ikisi de birbirine bağlıdır. Aslında bu faaliyetler, sürekli bir bilgi alışverişi 
sayesinde eş zamanlı olarak yapılmalıdır.

$\mathrm{Bu}$ aşama; muhtemel riskleri ve etkilerini izlemek amacıyla hazırlanan risk eylem planlarının yürütülmesi üzerine raporlar içerir. Risk durumlarının süreci, risk eylem planına bakılarak analiz edilir [49]. Risk kontrol yöntemleri, önceliklendirilmiş riskler dikkate alınarak proje sahibinin hedeflerine ve geliştirilen yazılım en az maliyetle gerçekleştirilmesine uygun olarak seçilmelidir. Sözkonusu yöntemler; risk kabulu, riskten kaçınma, riskin azaltılması ve riskin transferi olmak üzere dört başlık altında toplanmaktadır (Şekil 6) [48].

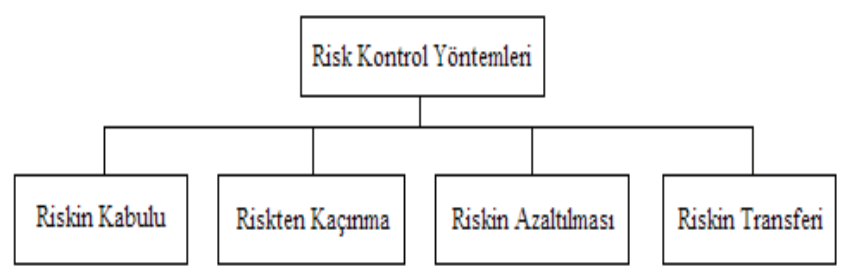

Şekil 6. Risk kontrol yöntemleri

\subsubsection{Riskin Kabulü}

Riskin varlığını kabullenerek geliştirilen yazılımı kullanmaktır [48]. Bir projedeki tüm tehditleri yok etmek genellikle mümkün olmadığ 1 için bu stratejinin benimsenmesi gerekli olabilir. Kabul etme stratejisi, proje ekibinin bu riskle başa çıkmak için poje yönetimi planını değiştirmemeye karar vermesi ya da başka bir uygun yanıt stratejisi belirleyememiş olması anlamına gelir. En yaygın aktif kabul stratejisi, riskle başa çıkmaya yönelik zaman, para ya da kaynak tutarları içeren beklenmedik durum yedekleri oluşturmaktır [50,51].

\subsubsection{Riskten Kaçınma}

Riskin oluşmasına sebebiyet veren etkenin yok edilmesidir. Örnek olarak, kullanılan yazılımda risk oluşturan bölümün yüklenmemesi veya kullanılmaması verilebilir [48]. Riskten kaçınma, bir projeyi negatif etkileyebilecek durumları önlemeyi amaçlar. Proje yönetimi planını, tehdidi tamamen devre dişı bırakacak şekilde değiştirmek gerekir. Proje yöneticisi, proje hedeflerini riskin etkisinden yalıtma ya da tehlike altında olan hedefi değiştirme yollarını da izleyebilir. Kaçınmaya örnek olarak, zaman çizelgesinin uzatılması, stratejinin değiştirilmesi ya da kapsamın azaltılması gösterilebilir. En radikal kaçınma stratejisi, projeyi tamamen durdurmaktır. Projenin erken bir aşamasında ortaya çıkan bazı risklerden, gereksinimler netleştirilerek, bilgi edinilerek, iletişim iyileştirilerek ya da uzmanlık bilgisi elde edilerek kaçınılabilir [50-51].

\subsubsection{Riskin Azaltılması}

Riskin gerçekleşmesi halinde oluşacak etkinin uygulanan kontroller ile azaltılmasıdır [49]. Riski azaltmak, olumsuz bir risk olayının olasılığını ve/veya etkisini azaltarak kabul edilebilir eşik sınırlarının içine çekmek anlamına gelir. Projede gereçekleşebilecek bir riskin olasıllğıını ve/veya etkisini azaltmak için erken bir aşamada eylemde bulunmak, genellikle risk gerçekleştikten sonra oluşan hasarı onarmaya çalışmaktan daha etkindir. Azaltma eylemlerine örnek olarak; daha az karmaşık süreçler benimsemek, daha çok test yapmak ya da daha istikrarlı bir tedarikçi seçmek gösterilebilir [51].

\subsubsection{Riskin Transferi}

Riskin oluşması durumunda meydana gelebilecek kaybı karşılayacak yöntemler bularak riskin başkalarına transfer edilmesidir. Sigorta yaptırmak veya kesin teminat mektupları gibi [48]. Risk transferi, tehdidin olumsuz etkisinin bir kısmını ya da tamamını, yanıtın sahipliğiyle birlikte üçüncü bir tarafa aktarmayı gerektirir. Riski transfer etmek, riski ortadan kaldırmaz, sadece riskin yönetilmesi sorumluluğunun başka bir tarafa devredilmesini sağlar [51].

\subsection{Risk İzleme}

Bu bölümdeki yeni eğilim, her ne kadar "Kontrol ve İzleme" şeklinde beraber ele alınması gerektiği yönünde ise de [52], çalışmada bu kısım "Risk İzleme" başlığı altında ayrı bir şekilde açıklanmıştır. Risk izleme, proje boyunca risk yanıt planlarının uygulanması, saptanan risklerin izlenmesi, artı risklerin izlenmesi, yeni risklerin saptanması ve risk süreci etkinliğinin değerlendirilmesi sürecidir [51]. Risk izleme süreci; projenin ve risk durumunun izlenmesi amacıyla, projeye ilişkin muhtemel değişikliklerin ve risk izleme ölçeklerinin sürekli kontrol edilmesini ifade etmektedir. Sürecin girdileri; risk izleme ölçekleri, risk yönetimi uygulama esasları, hedef nitelikleri ve analiz grafiğidir. Sonuçta elde edilecek durum raporları ise, süreç çıktılarını oluşturur. Sürecin yürütülmesi sorumluluğu proje yöneticisine aittir. Risk izleme süreci, projeye ilişkin ilk faaliyet başlatılınca hayata geçirilir. Uygulamada her ne kadar risk izleme süreci ikinci sırada başlatılan bir süreç olarak görünse de, risk izleme esasları büyük ölçüde risk tanımlama ve risk analizi süreçlerinde belirlenmektedir [14]. Sonuç olarak, Risk Yönetim Süreci'ndeki adımlara göre; sözkonsu adımların uygulanma teknikleri, sürece katılan kişiler, girdiler ve çıktılar Tablo 8'de özet bir şekilde verilmiştir. 
Tablo 8. Risk yönetim sürecindeki adımlara göre ayrıntılı bir analiz

\begin{tabular}{|c|c|c|c|c|}
\hline $\begin{array}{l}\text { Risk Yönetim } \\
\text { Süreç Adımları }\end{array}$ & $\begin{array}{l}\text { Uygulanan } \\
\text { Teknikler }\end{array}$ & Sürece Katılanlar & Girdiler & Çıktılar \\
\hline Risk Tanımlama & $\begin{array}{l}\text { Beyin Fırtınası } \\
\text { Simülasyon } \\
\text { Senaryo Analizi } \\
\text { Öngörüşmeler } \\
\text { Prototipleme } \\
\text { Kontrol Listeleri } \\
\text { Akış Şemaları } \\
\text { Uzmanlarla } \\
\text { Görüşmeler }\end{array}$ & $\begin{array}{l}\text { Proje Yöneticisi } \\
\text { Takım Üyeleri } \\
\text { Risk Yönetim Ekibi } \\
\text { Müşteriler } \\
\text { Ekip Harici Konu } \\
\text { Uzmanları } \\
\text { Paydaşlar } \\
\text { Risk Yönetimi Uzmanları }\end{array}$ & $\begin{array}{l}\text { Hedefler Kaynaklar } \\
\text { Zaman Cetveli Bütçe } \\
\text { Risk Yönetimi Uygulama } \\
\text { Esasları } \\
\text { Risk Kontrol Listeleri } \\
\text { Daha Önceki Projelerden } \\
\text { Öğrenilen Dersler }\end{array}$ & Risk Listesi \\
\hline Risk Analizi & $\begin{array}{l}\text { Metrikler } \\
\text { Karar Ağaçları } \\
\text { Senaryo Analizleri }\end{array}$ & $\begin{array}{l}\text { Proje Takım Üyeleri } \\
\text { Risk Yönetim Ekibi } \\
\text { Proje Yöneticisi } \\
\text { Başka Proje Yöneticileri } \\
\text { Uzmanlar }\end{array}$ & Risk Listesi & $\begin{array}{l}\text { Önceliklendirilmiş Risk } \\
\text { Senaryoları }\end{array}$ \\
\hline Risk Planlama & $\begin{array}{l}\text { Akış Şemaları } \\
\text { İşbirliği ile çalışma } \\
\text { Strateji Belirleme }\end{array}$ & $\begin{array}{l}\text { Proje Yöneticisi } \\
\text { Risk Yönetim Ekibi } \\
\text { Risk Yönetimi Uzmanları }\end{array}$ & $\begin{array}{l}\text { Risk Listesi } \\
\text { Analiz Sonuçları } \\
\text { Ön Planlar }\end{array}$ & $\begin{array}{l}\text { Strateji, } \\
\text { Seçenek ve Eylem Planları }\end{array}$ \\
\hline Risk Kontrolü & $\begin{array}{l}\text { Risk Kabulu } \\
\text { Riskten Kaçınma } \\
\text { Riskin Azaltılması } \\
\text { Riskin Transferi }\end{array}$ & Proje Yöneticisi & $\begin{array}{l}\text { K1smen Önceliklendirilmiş } \\
\text { Risk Senaryoları }\end{array}$ & $\begin{array}{l}\text { Seçilmiş Risk Kontrol } \\
\text { Eylemleri Risk İzleme } \\
\text { Ölçekleridir }\end{array}$ \\
\hline Risk İzleme & $\begin{array}{l}\text { İzleme ve Değerlen- } \\
\text { dirme }\end{array}$ & Proje Yöneticisi & $\begin{array}{l}\text { Risk İzleme Ölçekleri } \\
\text { Risk Yönetimi Uygulama } \\
\text { Esasları } \\
\text { Hedef Nitelikleri } \\
\text { Analiz Grafiği }\end{array}$ & Durum Raporları \\
\hline
\end{tabular}

\section{SONUÇ VE ÖNERILER}

$\mathrm{Bu}$ çalışmada, proje yönetimi kapsamında risk tanımı, risk faktörleri, risk türleri, risk stratejileri ve risk yönetim süreci ayrıntılı ve karşılaştırmalı bir şekilde bilimsel olarak ele alınmıştır. Böylece, yazılım riskleri ve bu riskleri önleme yöntemleri ortaya konarak herhangi bir yazılımda oluşabilecek risklerin ortadan kaldırılması veya en azından azaltılması yönünde atılması gereken adımlar açıklığa kavuşturulmuştur.

Yapılan araştırmada, yazılım risklerinin eksiksiz bir şekilde belirlenmesinin ve projelerde risk yönetim sürecinin uygulanmasının önemli olduğu anlaşılmıştır. Önemli görülen bir başka konu ise, yazılım risk yönetim süreçlerinin başarılı bir şekilde sonuçlanması için, geliştirilecek olan yazılımların riskleri mümkün olduğunca iyi belirlenmesi ve bu konudaki standart ve süreçlerin eksiksiz bir şekilde uygulanması gerektiğidir.

Yine araştırmaların çoğunda, yazılım projelerinde risk tanımlama ve risk yönetim faaliyeti sadece bir yöntem olarak sınırlandığı, yazılım projelerinde karşıllaşılan risklerin genel olarak iyi değerlendirilemediği veya yönetilemediği

ve risk yönetim sürecindeki eksikliklerin yazılım projelerini önemli ölçüde etkilediği ortaya çıkmıştır. Bu sorunların giderilebilmesi için proje yöneticilerinin; karşılaşacakları sorunlar konusunda yeteri kadar öngörüye sahip olmaları ve belirli bir risk yönetim metodunu kullanmaları gerekmektedir.

Ayrıca, uygun bir şekilde tanımlanmış risk yönetim süreç modeli için çeşitli risk türleri önceliklendirme yapılarak öncelik sırasına koyulmalıdır. Tanımlanan risklerin, daha düşük geliştirme maliyeti ile yönetilmesi için; mümkün 
olduğunca erken bulunması gerekmektedir. Risklerin reaktif olmasını önlemek için potansiyel tehlikeler kontrol edilmeli ve azaltılmalıdır. Böylece, gelecekte oluşabilecek birçok ciddi problemden sakınılır.

Burada ortaya çıkan ve özellikle dikkat edilmesi gereken bir diğer husus da, risk analiz süreci tamamlandı̆̆ında sonuçların bir rapor halinde hazırlanması gerektiğidir. Çünkü sözkonusu rapor, proje yöneticileri tarafından yöntem ve teknikte, bütçe ve zaman planlamasında; genel olarak yönetim faaliyetlerinde karar verirken kullanılmaktadır. Aynı zamanda sözkonusu rapor, yöneticinin risk yönetim faaliyetlerini başarılı bir şekilde sürdürmesinde önemli ölçüde etkili olmaktadır.

\section{KAYNAKLAR}

[1] Gürbüz, A. (2010) Yazılım Test Mühendisliği, Papatya Yayıncılık Eğitim, İstanbul, 31,34.

[2] Abak, A. T. (2012) Yazılım Proje yönetimi: Hızlı ve Kaliteli Yazılım Ürünü Gerçekleştirme Stratejileri, www.bilisimzirvesi.com.tr/01/dosyalar/yazilim-projeyonetimi.pdf.

[3] Erdemir, U., Tekin, U., Buzluca, F. (2008) Nesneye Dayalı Yazılım Metrikleri ve Yazılım Kalitesi, Yazılım Kalitesi ve Yazılım Geliştirme Araçları Sempozyumu (YKGS08), İstanbul.

[4] ISO/IEC 9126-1: (1999) Information Technology Software Product Quality - Part 1: Quality Model. ISO/ IEC JTC1/SC7/WG6.

[5] Younis, A. E. (2011) Yazılım Projelerinde Risk Yönetimi, Yüksek Lisans Tezi, Bilgisayar Bilimleri, Gazi Üniversitesi Bilişim Enstitüsü, Ankara, Mayıs.

[6] Sommervile, I. (2000) Software Engineering, New York: Addison-Wesley, Harlow, England.

[7] Dedolph, F.M. (2003) The neglected management activity: Software risk management, Bell Labs Technical Journal, Volume 8 Issue 3, (Dec), 91-95.

[8] Milli Eğitim Bakanlığı, (2011) Ulaştırma Hizmetleri, Risk, Rapor, Ankara.

[9] Yong. H., Xiangzhou. Z., Xin. S., Mei. L., Jianfeng . D. (2009) An Intelligent Model for Software Project Risk Prediction, International Conference on Information Management, Innovation Management and Industrial Engineering, ICIII, vol. 1, pp.629-632.

[10] Tang. A., Wang. R. (2010) Software Project Risk Assessment Model Based on FuzzyTheory, Computer and Communication Technologies in Agriculture
Engineering (CCTAE), 2010 International Conference On 12-13 June 2010, pp 328-330.

[11] Robert. N. C. (1996) Large-Scale Project Management is Risk Management, IEEE Software.

[12] Tiftik, N., Öztarak, H., Ercek, G. ve Özgün, S., "Sistem/ yazılım geliştirme sürecinde doğrulama faaliyetleri”, III.Ulusal Yazılım Mühendisliği Sempozyumu, Ankara, 1-2 (2007).

[13] İnternet: Leman Türkoğlu, "Proje Yönetimi”, www. lemanturkoglu.com/cc/1002167/.../File/tbd_genc_ sunumu.ppt, 2012.

[14] Gülebağlan, S. (2006) Yazılım Geliştirmede Risk Yönetimi, Yüksek Lisans Tezi, Çanakkale Onsekiz Mart Üniversitesi, Fen Bilimleri Enstitüsü.

[15] Boehm, B.W. (1991) Software Risk Management: Principle and Practices, IEEE Software, Vol. 8, No. 1, January 1991.

[16] Abdelrafe, E., Burairah, H. (2011) Managing Software Project Risks with Proposed Regression Model Techniques and Effect Size Technique, International Review on Computers \& Software, Mar2011, Vol. 6 Issue 2, p.250.

[17] Cao, X. (2006) A cross-culture study of risk management in software projects, ProQuest Dissertations and Theses; 2006; ProQuest Dissertations \& Theses (PQDT), May 2006.

[18] Higuera, RP and YY Haimes (1996). Software risk management(CMU/SEI-96-TR-012, ESC-TR-96-012). Pittsburgh: Software Engineering Institute, Carnegie Mellon University.

[19] Conrow, EH and PS Shishido (1997). Implementing risk management on software intensive projects. IEE Software, 14(3), 83-89.

[20] Kansala, K (1997). Integrating risk assessment with cost estimation. IEEE Software, 61-67.

[21] Natarajan, K. V. (2004) Efficient software development, Proceedings of MASPLAS'04, Mid-Atlantic Student Workshop on Programming Languages and Systems, Seton Hall University.

[22] Westfall, L. (2001) Software Risk Management, The Westfall Team, PMB 383, 3000 Custer Road, Suite 270, http://westfallteam.com/Papers/risk_management_ paper.pdf, [17 Mayıs 2014].

[23] Bodea, C. \& Dascalu, M. (2009) Modeling Research Project Risks with Fuzzy Maps. JAQM - Journal of Applied Quantitative Methods, 4(2).

[24] Hoodat, H., Rashidi, H. (2009) Classification and 
Analysis of Risks in Software Engineering, World Academy of Science, Engineering and Technology, 56.

[25] Erdem, O.A. ve Younis, A. E. (2012) Yazilım Projelerinde Risk Yönetimi, Gazi Üniversitesi Bilişim Teknolojileri Dergisi, Cilt: 5, Sayı: 1.

[26] Pressman, R. S. (2005) Software Engineering: A Practitioner's Approach, 6th Ed., Mc Graw Hill, Singapore, 480-481, 492.

[27] Wiegers, K.E. (2000) Know Your Enemy: Software Risk Management, http://www.process impact.com [12 Ocak 2005].

[28] Şenyurt, H. (2006) ISO/IEC Yazılım Yasam Döngüsü Süreçleri - Risk Yönetimi Standartları: ISO/IEC Software Life Cycle Processes - Risk Management Standards, TÜBITTAK UEKAE / İLTAREN.

[29] Richard, F. (1994) Risk Management for Software Projects, IEEE Software.

[30] Chittister, C., Haimes, Y.Y. (1993) IEEE Transactions on Systems, Man, and Cybernetics, Vol.23 No 3.

[31] Rockwell (1995) Risk Management, Rockwell Job Aid.

[32] IEEE 1540, (2001) IEEE 1540 Standard for Lifecycle Processes-Risk Management. IEEE, New York, NY.

[33] Institute of Risk Management (2002) Association of Insurance and Risk Managers, National Forum for Risk Management in the Public Sector, A Risk Management Standard. IRM, UK.

[34] Project Management Institute (2004) A Guide to the Project Management Body of Knowledge (PMBoK), 3rd Ed. ANSI/PMI 99-001-2004, PMI, Newton Square, PA.

[35] Standards Australia and New Zealand, Australian/New Zealand Standard (2004) Risk Management AS/NZS 4360:2004. 3rd Ed., Stds Australia/New Zealand.

[36] Boehm, B.W. (1988) A spiral model of software development and enhancement. IEEE Computer 21 (5), 61-72.

[37] ISO/IEC 15.504-5 (1999) Information TechnologySoftware Process Assessment- Part 5: An Assessment Model and Indicator Guidance. International Standard Organization.

[38] MSF-Microsoft (2002) Microsoft Solutions Framework: MSF Risk Management Discipline v. 1.1: Microsoft. Available in: http://www.microsoft.com/ msf.

[39] RUP - Rational Software Corporation (2003) Rational unified process: best practices for software development teams. Rational Software White Paper,TP026B, Rev
11/01: IBM. Available in: http://www.ibm.com.

[40] ISO-International Organization for Standardization (2003) ISO 10.006:2003 - Quality Management Systems-Guidelines for Quality Management in Projects. International Standard Organization.

[41] AS/NZS 4360 (2004) Standards Australia and standards New Zealand. Risk Management. Sydney, NSW.0 733759041.

[42] SEI, Software Engineering Institute (2006) CMMI ${ }^{\circledR}$ for Development. Staged Representation, Version 1.2, Technical Report (06tr008).Software Engineering Institute, Carnegie Mellon University, Pittsburgh, PA (Available in: http://www.sei.cmu.edu/reports/06tr008. pdf.

[43] SOFTEX—Associação para Promoção da Excelência do Software Brasileiro (2006) MPS.BR - Melhoria de processo do software brasileiro, versão 1.1, maio 2006: Softex. Available in: www.softex.br.

[44] PMBOK (2008) Proje yönetimi bilgi birikimi klavuzu, 4. Bask1, PMI.

[45] Barros, M.O., Werner, C.M.L., Travassos, G.H. (2004) Supporting risks in software project management. Journal of Systems and Software. 70, 21-35.

[46] Carr, M.J., Konda, S.L., Monarch, I.A., Ulrich, F.C. and Walker, C.F. (1993) Taxonomy- BasedRisk Identification, SEI Technical Report SEI-93-TR-006, Pittsburgh, PA: Software Engineering Institute.

[47] Kajko-Mattsson, M., Nyfjord, J. (2008) State of software risk management practice, LAENG International Journal of Computer Science, November.

[48] Eskiyörük, D. (2007) BGYS - Risk Yönetim Süreci Klavuzu, Sürüm1.00, Ulusal, Elektronik ve Kriptoloji Araştırma Enstitüsü.

[49] Moeinzadeh, P. ve Hajfathaliha, A. (2009) A combined fuzzy decision making approach to supply chain risk assessment", World Academy of Science, Engineering and Technology, No.60, ss.519-535.

[50] Bannerman, L. P. (2008) Risk and risk management in software projects: A reassessment, The Journal of Systems and Software, 81, 2118 - 2133.

[51] Boehm, B., Turner, R. (2003) Using risk to balance agile and plan-driven methods.Computer 36 (6), 57-66.

[52] PMBOK (2012) Proje yönetimi bilgi birikimi klavuzu, 5. Bask1, PMI. 